\title{
Post-occupancy evaluation of pilgrims' accommodation: a case study of Mina in Makkah city
}

\author{
A. M. A. Shehata $^{1}$ \& A. M. Z. Elzawahry ${ }^{2}$ \\ ${ }^{1}$ Effat University, Saudi Arabia \\ ${ }^{2}$ Umm Al-Qura University, Saudi Arabia
}

\begin{abstract}
Every year, the city of Makkah in Saudi Arabia receives $\sim 3$ million pilgrims. In the course of a 10-day visit, pilgrims typically spend about 4 days in Mina, which is a district in Makkah city. Accommodation units in Mina are light single-floor structures, partitioned with fiberglass fabric. As a result of this huge demand for accommodation, the net area per pilgrim has been reduced to $1.2 \mathrm{~m}^{2}$. To increase pilgrims' housing facilities in Mina, the Saudi government has launched a new initiative entailing the construction of apartment buildings comprising 13 floors in mountainous areas. The primary aim of this study was to appraise the quality and performance characteristics of this evolving residential environment through assessments of the satisfaction levels of their residents. This post-occupancy evaluation focused on users' satisfaction relating to design, function, services, and the environment. To achieve the study's objectives, activities were monitored and waiting times for building services were recorded. Performance indicators were selected in relation to design, capacity, functions, and environment. This is significant in maximizing the residents' satisfaction of any future expansions' design proposals.
\end{abstract}

Keywords: accommodation, Mina, performance, pilgrimages'satisfaction, postoccupancy evaluation.

\section{Introduction}

When undertaking the Hajj pilgrimage, Muslims visit Makkah and holy places located in its vicinity. This annual pilgrimage, which attracts more than 2.5 million people from across the globe, commences between the eighth and thirteenth day 
of the Dhul-Hijja month of the Islamic lunar calendar. Pilgrims have to spend 4 of these 6 days in Mina, a valley that extends $6 \mathrm{~km}$ to the east of central Makkah (as shown in Figure 1). The increasing numbers of pilgrims place further strain on Mina's accommodation capacity, which is limited to accommodate 1.3 million pilgrims. The net area allocated for pilgrims has been reduced and all hilly areas have been used to increase the accommodative capacity. To overcome space limitations and temporal constraints, urban designers and decision makers have examined the feasibility of expanding construction on the steep mountains to the north and south of Mina's valley. A Build, Operate and Transfer pilot project was initiated on the northern mountain in Mina to accommodate about 13,000 pilgrims, and a new housing development project in the area of the mountain is about to be tendered.

\subsection{Characteristics of Mina's built environment}

The satellite image of Makkah city (shown in Figure 1), illustrates Mina's location in relation to Makkah city. Mina is located at $6 \mathrm{~km}$ to the east of Makkah city; with an area of $8.12 \mathrm{~km}^{2}$. As shown in the figure Mina's valley is defined by mountains to the north and south. Mina's valley is $3 \mathrm{~km}$ in length by $1.5 \mathrm{~km}$ in width, with an elevation varying from $270 \mathrm{~m}$ to $320 \mathrm{~m}$ above sea level. Steep mountains rise around the valley at elevations up to $1000 \mathrm{~m}$ above sea level. Only $52 \%$ of Mina's area is developed flat land, while the rest is mountainous. Urban development has extended over almost all over the valley's flat area. Consequently, there is little remaining space for expansion $[1,2]$.

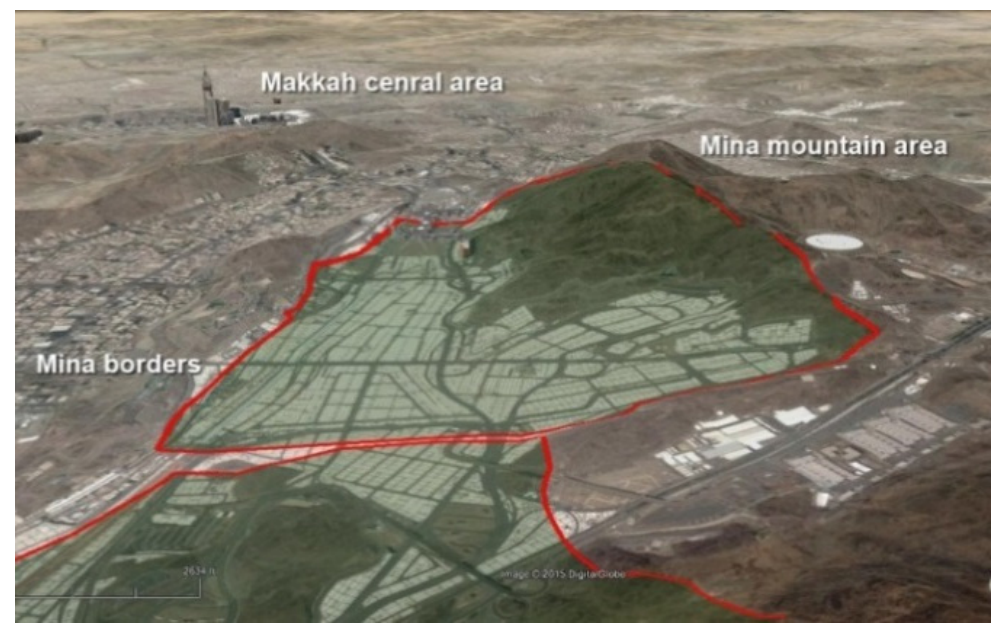

Figure 1: $\quad$ Satellite image of Mina's area [4].

\subsection{Accommodation in Mina}

Mina is regarded as the world's largest tent city, accommodating around 2 million pilgrims. It is unique in several respects. First, the area is visited by pilgrims during 
just 3 days each year. Second, Mina has defined religious, spatial, and temporal boundaries. Third, no permanent buildings for accommodation are permitted within Mina's boundaries.

Mina's built environment consists of four components. The first entails light housing structures comprising tents made of fabric and fixed to concrete foundations. The second entails concrete structures that constitute service buildings such as public toilets, police stations, and medical facilities. The third comprises infrastructure related to utilities such as water tanks and electric transformers. The final component is a traffic network made up of roads and bridges $[1,3]$.

\section{Post-occupancy evaluation of residential buildings (POE)}

POE is a structured approach used for evaluating the operational performance of buildings after they have been occupied [5]. Several evaluation frameworks for evaluating residential projects were developed by international organizations. Trupin argued that POE types can be classified into indicative, investigative and diagnostic. Figure 2 illustrates the tools, aims characteristics of each one of these three approaches [6].

Koichi also argued that the framework for evaluating hotels and touristic accommodations has two different types of criteria; the first one is numerical based criteria like location, money value, food service, rooms and utilities; and subjective ones like bathroom, service quality and staff responses. This evaluation framework is presented in Figure 3 [7].

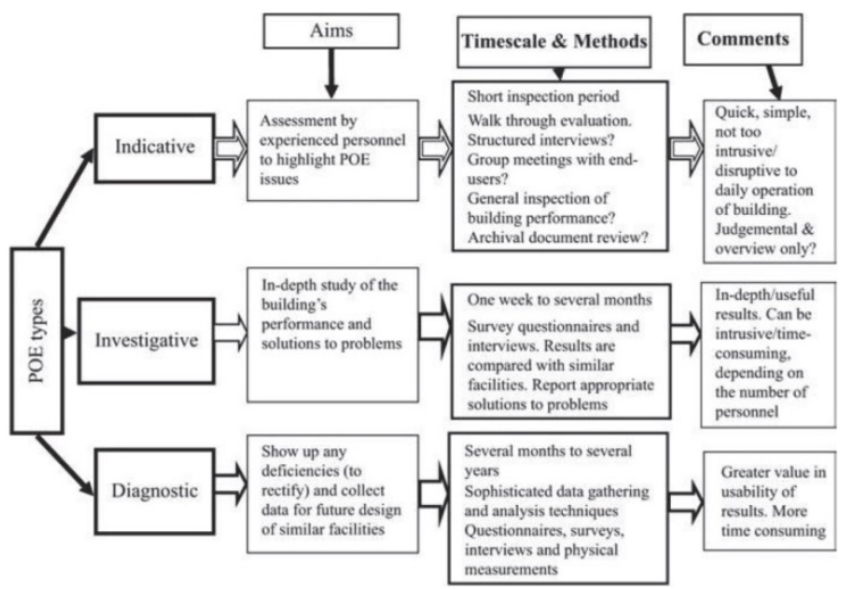

Figure 2: $\quad$ Types, aims and tools of post occupancy evaluation [10]. 


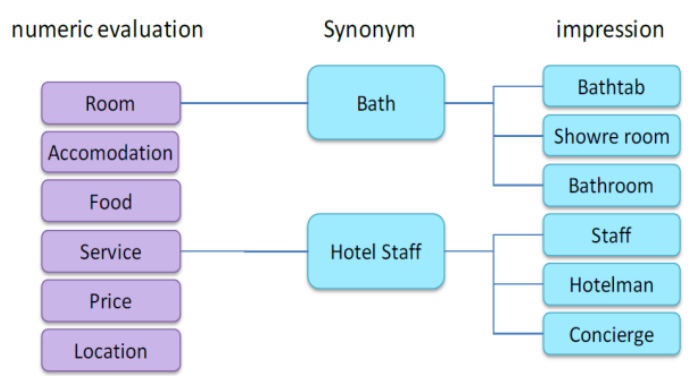

Figure 3: Evaluation criterion of users' satisfaction based framework [11].

\subsection{Users' satisfaction approach}

Empirical studies have investigated the close relationships between the physical environment and building occupants' overall satisfaction with their living arrangements [8]. In general, physical environment can be assessed in terms of the following main criteria; location layout, utilities, services, and supporting facilities. These functional components have a significant impact on residents' satisfaction [9].

Residential buildings should not only be suited to the requirements of users, but should also enable functionality to ensure residents' satisfaction. Housing should help and support its residents (pilgrims) to perform their spiritual ceremonies in peace and comfort.

\subsection{Mina's accommodation evaluation framework}

Figure 4 proposes an evaluation framework with four tools complementing each other for Post Occupancy Evaluation of the newly developed pilgrims' accommodation in Mina. The four tools are:

1. Examining buildings documents against the standards and codes.

2. Investigating Pilgrims' degree of satisfaction using a predesigned questionnaire.

3. Observing services' rates through documenting activities using observation forms.

4. Checking operational processes through interviewing operators about their operational preferences and modifications thy made to fulfil their operational requirements.

It is worth mentioning that this paper presents the users satisfaction based evaluation of "Mina's newly developed accommodation. 


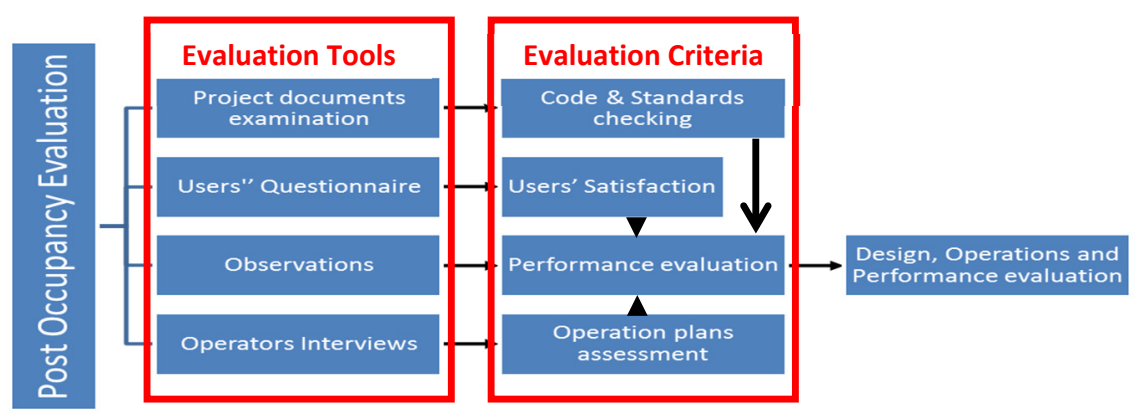

Figure 4: Framework for pilgrims' accommodation post occupancy evaluation.

\subsection{Performance indicators}

The design configuration of building components supports different users. These components include the gathering space, the layout of entrances, vertical and horizontal circulation elements for facilitating users to find their way, and the provision of personal spaces for maintaining privacy [10]. Consequently, spatial planning, privacy, fixtures and furniture are all architectural aspects of managing facilities that are associated with the quality of residents' experiences. The pilgrims spend most of their time within the buildings' public spaces. The provision of adequate space could evidently increase their level of comfort. Conversely, small and badly located spaces would be more likely to create dissatisfaction $[11,12]$. Therefore, indicators relating to the following aspects were used to measure users' satisfaction in this study:

- Indicators related to site and location: Because the project is located on Mina's mountainous part, site indicators include accessibility, spatial relation to other destinations, internal circulation, loading areas, and parking lots.

- Indicators related to the main building functions: Based on the pilot survey, indicators cover the building entrance and egress, horizontal and vertical circulation, salons and the reception area, prayer areas, bathing areas and toilets, catering facilities, and bedrooms.

- Indicators focuses on operation, maintenance, and management: They cover loading and unloading services, storage areas, vertical circulation systems, air conditioning, housekeeping, electrical and artificial lighting, and signage systems $[13,14]$.

\section{Case study: Mina's pilot housing project}

Located on a mountain north of the valley, Mina's pilot housing project was initiated in 2004. Six buildings were constructed on 1.3 ha, with a total built-up area of $87,000 \mathrm{~m}^{2}$. Figure 5 shows the project's location and spatial layout.

Each building contains 10 floors for accommodation and three additional service floors. The construction was completed in 2008 and began to be used during the same year. 


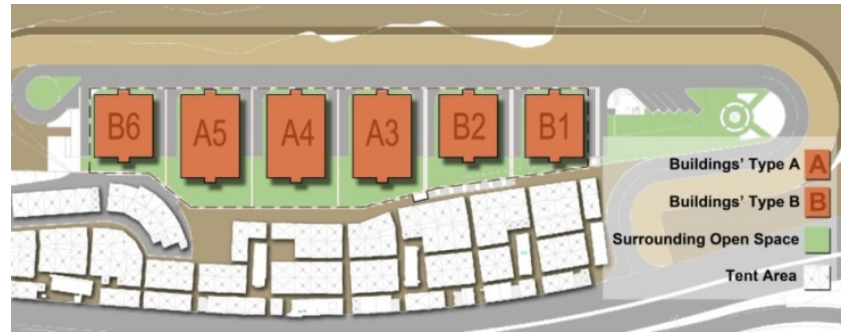

Figure 5: Site plan of pilot housing project in Mina (the author).

\subsection{Site plan}

The pilot project site is situated at an elevation of $20 \mathrm{~m}$ above the valley, which is where all of the pilgrimage activities take place. The site is served by a cul de sac that is solely dedicated to the conveyance of the project's residents. Another pedestrian access point connects the site to Al-Jamarat Bridge. Additionally, a stairway connects the site to the valley. Figure 5 depicts the project site layout in relation to the valley while figure 6 shows general view of the project and its relation to surroundings.

\subsection{Buildings' plans}

A typical floor plan includes core central services (elevators, staircases, and electromechanical rooms) and identical bedrooms, each covering $32 \mathrm{~m}^{2}$, including bathrooms, located along the perimeter of the building shown in figure 7. As shown in Figure 8, the ground floor includes a large outdoor area designed for luggage loading and unloading. It was observed that some of the pilgrims' activities were also performed in these areas. It is noteworthy that the main staircase only serves the first two floors, typically leading out of the building.

Fig. 9 shows that the original design of the first floor of Type B buildings had sex-segregated lounges and prayer halls. In addition to providing necessary toilets, the project implementers made some modifications relating to the use of spaces on this floor. They converted the female lounge and prayer hall into workers' rooms. Moreover, they converted the male lounge into a restaurant for men. As Figure 10 shows, the original design of the second floor had separate male and female dining halls, a kitchen, and offices. The project implementers expanded the kitchen to take the place of the female dining hall, and changed the male dining hall into a female dining hall. The final outcome of the modifications was to dispense with the female prayer hall and the gender differentiated lounges, while simultaneously enlarging the two sex-segregated restaurants, as well as the kitchen. 


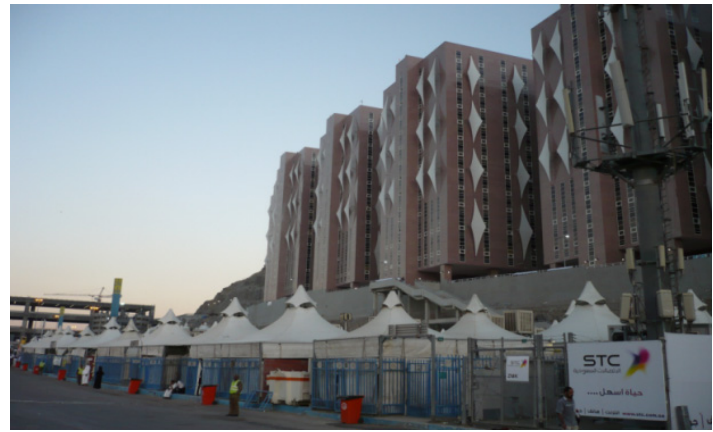

Figure 6: General view of Mina's pilot housing project and its surroundings.

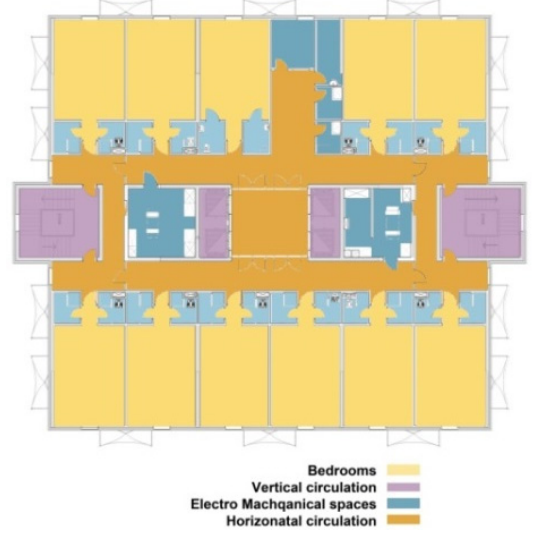

Figure 7: Typical floor plan.

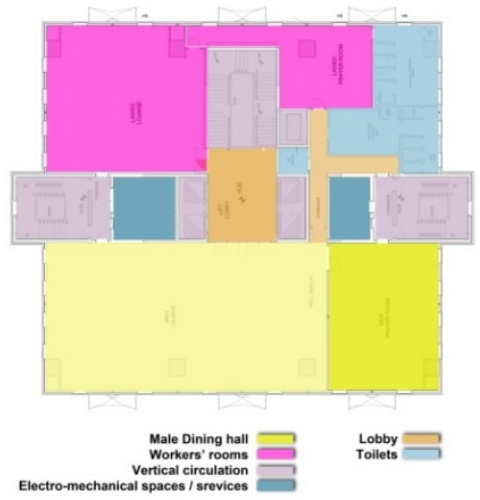

Figure 9: First floor plan.

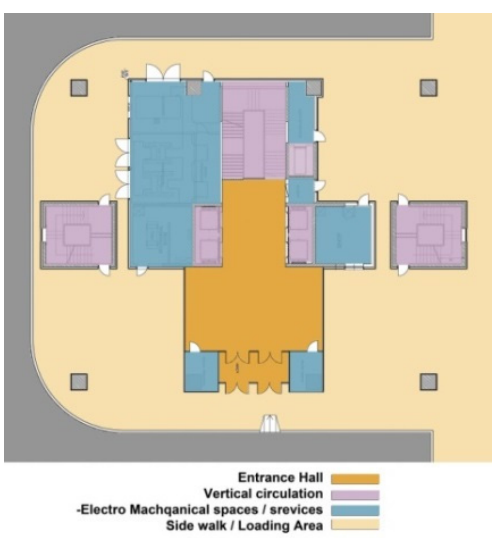

Figure 8: Ground floor plan.

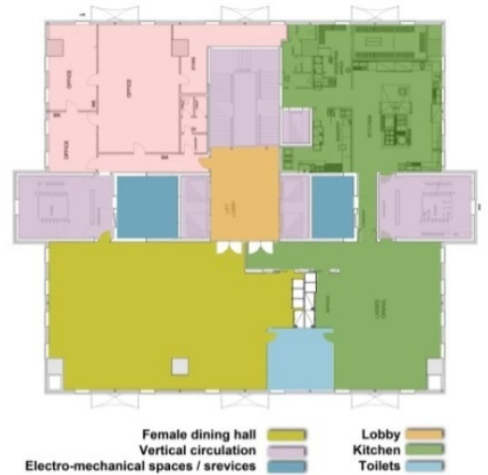

Figure 10: Second floor plan. 


\section{Users' satisfaction analysis}

Several indicators relating to building layouts and entrances were measured. These included accessibility, loading and unloading, reception, availability of a parking area for buses, and assembly locations [12]. Two peak periods of activity were identified during the evaluation period. Both of these were associated with activities relating to the pilgrims' arrival. The first peak was evident during the eighth day of the month of Dhul-Hijja and the second was observed during the tenth day of Dhul-Hijja. The serving road design was that of a cul-de-sac, with no dedicated parking area for buses. This caused traffic jams within 2 hours of the arrival of pilgrims. Consequently, pilgrims had to walk for long distances, carrying their own luggage.

The chart in figure 11 reveals that $28 \%$ of the pilgrims indicated that their most dissatisfactory experience was related to traffic jams and reaching the building. A total of $21 \%$ of the pilgrims found overcrowding at the building entrance upon their arrival to be the most dissatisfying experience. The second chart in figure 12 indicates that the first day (arrival day) in Mina was the most dissatisfactory day in relation to all of the indicators associated with the site layout, building entrances, and arrival-related services.

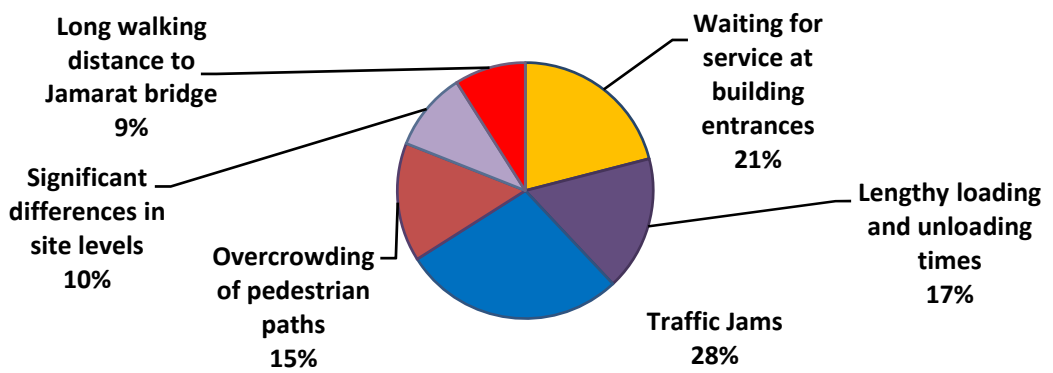

Figure 11: Reasons for users' dissatisfaction with the layout facilities.

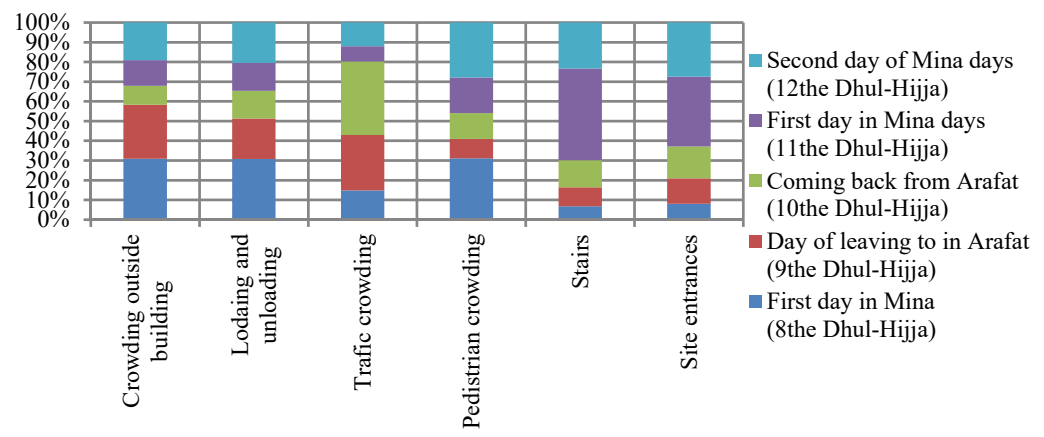

Figure 12: Issues causing dissatisfaction according to pilgrimage days. 


\subsection{Accommodation facilities}

The main indicators used to evaluate users' satisfaction were related to bedrooms. They were: area sufficiency; quality, design efficiency, and flexibility of furniture; and suitability of bathrooms. It is noteworthy that there were different architectural designs for the same room area $\left(33 \mathrm{~m}^{2}\right)$. Accommodative capacities, for the same area, also varied between 12 and 18 persons. The net area per person ranged between 2.75 to $1.83 \mathrm{~m}^{2}$. This ratio exceeded the mandatory $1.2 \mathrm{~m}^{2}$ entailed in the original standard housing ratio for Mina's tents. The toilet ratio was one toilet for eight persons.

The first chart in Figure 13 indicates that $50 \%$ of pilgrims were housed in rooms accommodating more than 16 persons. The results shown in the charts reveal that between $66 \%$ and $72 \%$ of the residents were satisfied with the area of their room, its furniture and finishing, and the bathroom.

\subsection{Catering facilities}

The original building design included two dining halls covering a total area of 310 $\mathrm{m}^{2}$. These comprised a dining hall and attached kitchen with an area of $135 \mathrm{~m}^{2}$. The net area ratio per pilgrim was $0.25 \mathrm{~m}^{2}$.

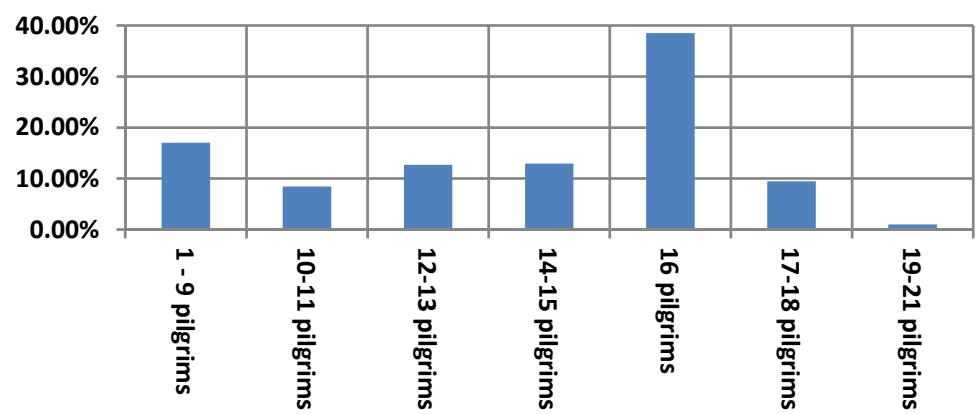

Figure 13: Housing occupancy rates.

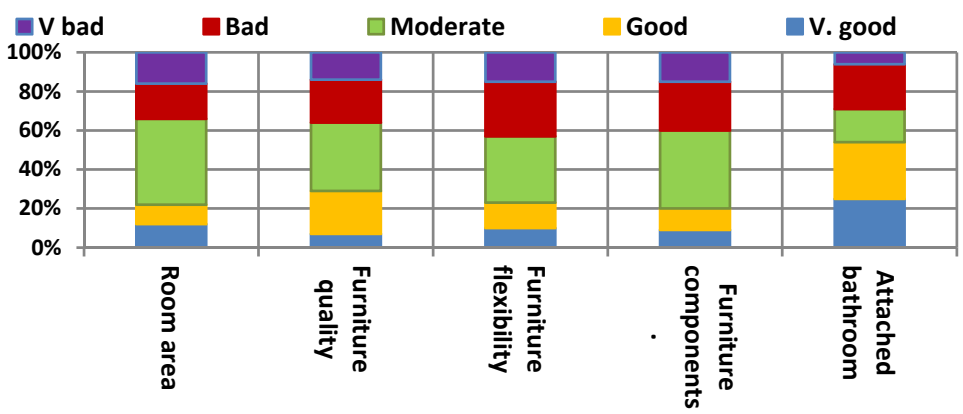

Figure 14: Housing facilities users' satisfaction with housing facilities. 
During the project's implementation, as per the plans shown in Figures 9 and 10 , one of the two dining halls was moved from its original location on the second floor to the first floor. This extended the dining area and kitchen area to $456 \mathrm{~m}^{2}$ and $268 \mathrm{~m}^{2}$, respectively, with a total area ratio of $0.40 \mathrm{~m}^{2} /$ resident. It may be worth mentioning here that the restaurant ran a self-service open buffet. However, the dining hall had no service entrance. Moreover, this area was not adequate for catering to the large number of pilgrims.

The charts in Figure 15 depict pilgrims' satisfaction relating to catering facilities. The following conclusions can be derived:

- A total of $44 \%$ of the residents did not use the restaurant because it was overcrowded.

- A total of $90 \%$ of restaurant users reported overcrowding.

- A total of $55 \%$ of users noted that the queuing time to find an empty spot took about 18 minutes, while obtaining service usually took approximately 12 minutes.

- Both the food hall and the kitchen were perceived as being inadequate by $56 \%$ of the restaurant users.

\subsection{Horizontal and vertical circulation}

It should be noted that the buildings each had 13 floors. Thus, it is important to evaluate the efficiency and adequacy of operational plans for the elevators.

Figure 17 graphically depicts findings on users' satisfaction regarding elevator services that are based on direct observations and their timing during pilgrimage days. These reveal that:

- $35 \%$ of the users waited for 5 minutes to use the elevator service.

- $37 \%$ of users waited for between 5 and 10 minutes to use the elevator service.

- $18 \%$ of users waited for more than 10 minutes to use the elevator service.

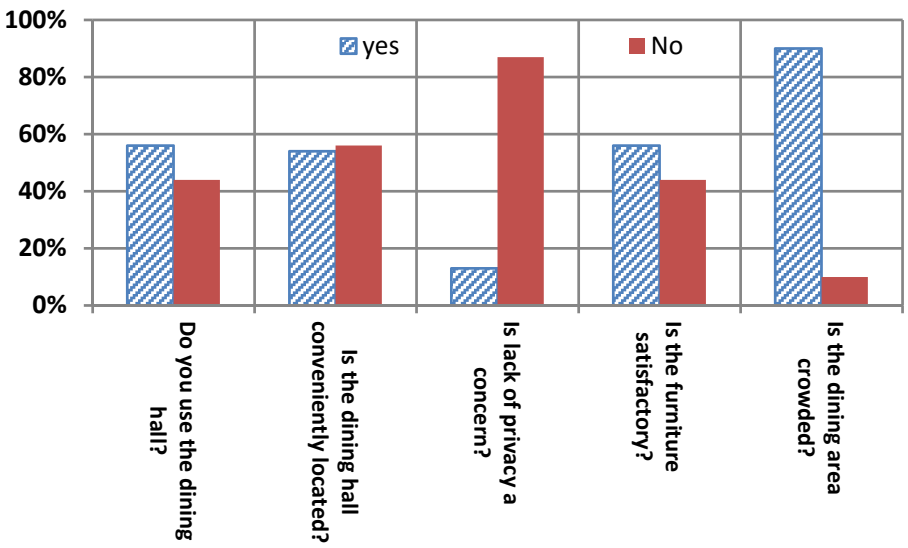

Figure 15: $\quad$ Pilgrims' satisfaction relating to catering facilities. 
The following design-related issues were observed for the building staircases:

- The main staircase (served just the first three floors and not the entire building.

- Users were confused by discontinued staircases, which seriously hindered them from finding their way within the building.

- When pilgrims move between their rooms located in typical floors to services located in first floor, they have to use the emergency stairs.

\subsection{Salons and public spaces}

The project implementers modified all salons and public spaces. Consequently, the residents had to use the buildings' entrance halls and surrounding sidewalks as salons. Because of the lack of such important spaces, $25 \%$ of the residents indicated that they used the prayer and catering halls as social spaces. This was observed to have significant adverse impacts on the functionality of these spaces.

\subsection{Religious facilities}

According to the original design layout, separate male and female prayer halls (respectively, $99 \mathrm{~m} 2$ and $67 \mathrm{~m} 2$ ) were located on the first floor of the building. However, the female prayer hall was closed down after operations began. Consequently, female residents had to perform their prayers in their bedrooms. Because of the limited space for prayer, additional male prayer spaces (see Figure 9) were allocated within the surrounding area.

Indicators for the prayer area included the location of the prayer, hall, the prayer area, the suitability of the ablution area, and crowding. Figure 18 presents the findings for the most significant indicators. It reveals that $56 \%$ of male users were dissatisfied with prayer halls in terms of locations and spatial relationships to other functional building components. The level of dissatisfaction relating to associated sanitary services was not the same as for the prayer halls, because pilgrims used toilets located within their bedroom areas.

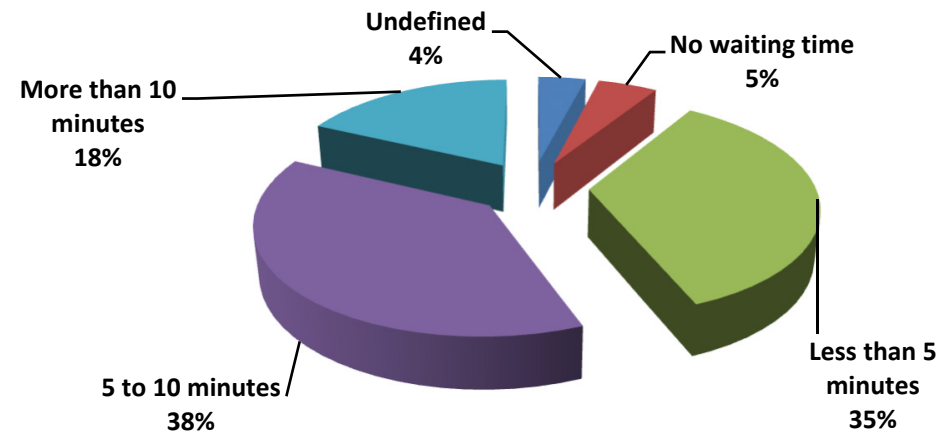

Figure 16: Users' satisfaction relating to elevator waiting times. 


\subsection{Services and utilities}

The building plans (shown in Figures 7, 8, 9, and 10) reveal a lack of storage area and the absence of a garbage chute and service elevators. The photographs presented in Figures 19 and 20 specifically show the lack of service elevators and storage areas. An evaluation of users' satisfaction, presented in Figure 19, revealed that $15 \%$ were not satisfied with the air conditioning system control.

Moreover, $40 \%$ of residents reported that their mobile phones did not function within the building spaces, and $15 \%$ of residents were dissatisfied with the building communication systems.

An evaluation of indicators relating to the management of facilities, presented in Figure 20, showed that approximately $60 \%$ of the pilgrims were dissatisfied with the housekeeping, room service, kitchen service, and the maintenance of public spaces.

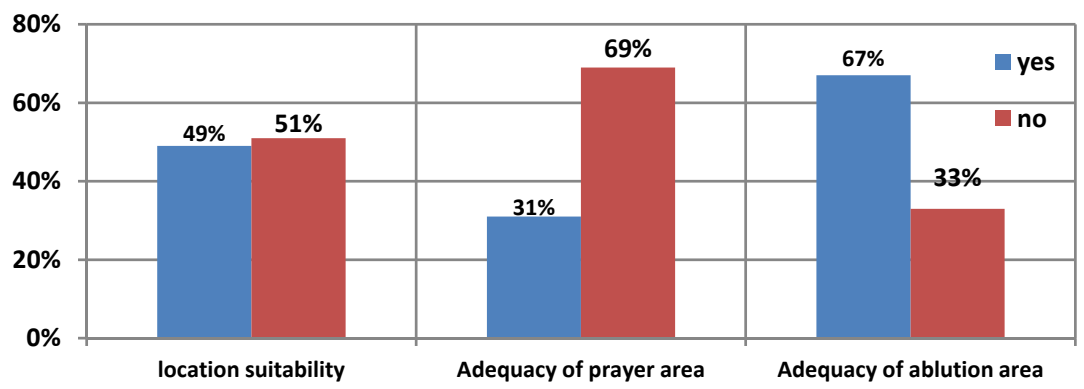

Figure 17: Users' satisfaction relating to prayer spaces.

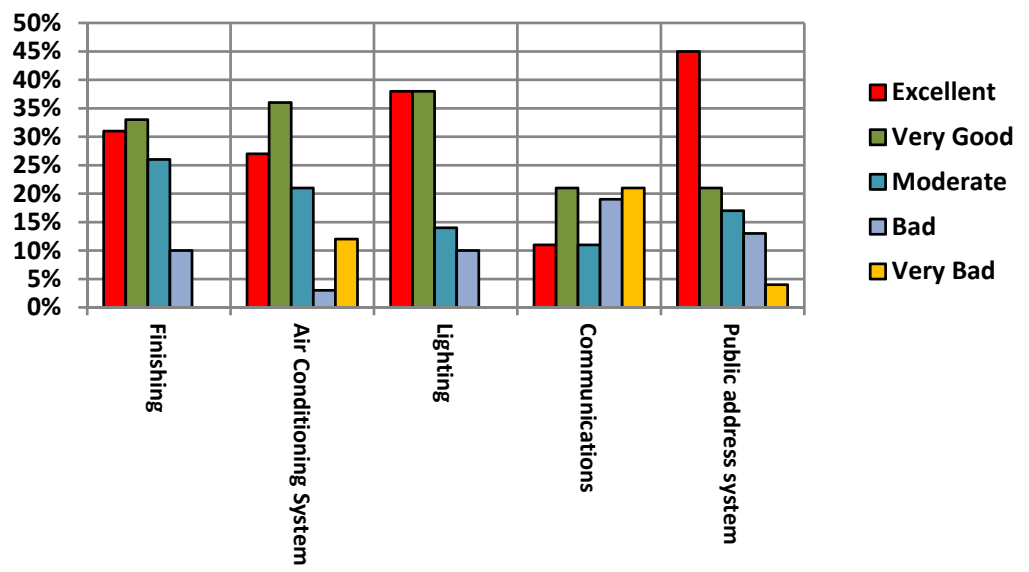

Figure 18: Users' satisfaction building relating to systems and finishing. 


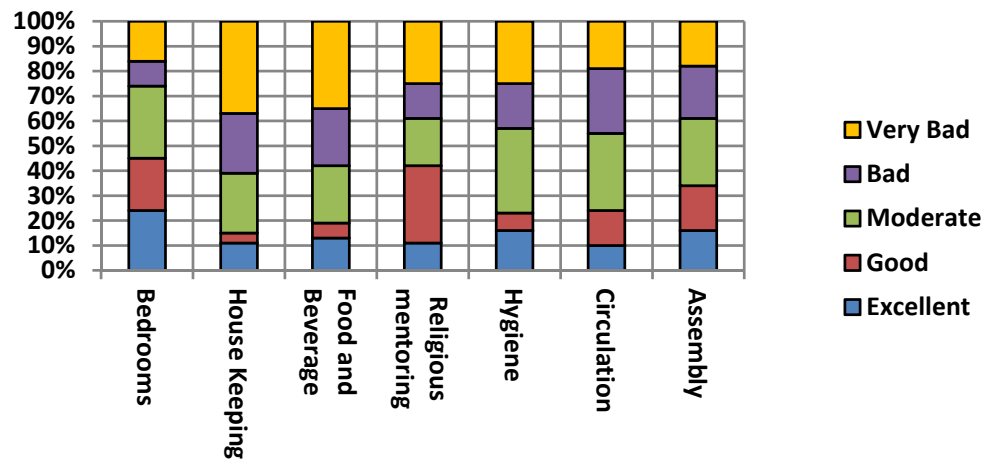

Figure 19: Users' satisfaction relating to management, operation.

\subsection{Overall assessment}

Users were asked about their overall pilgrimage experience. Figure 21 provides a summary of the results for key indicators relating to overall users' satisfaction. These indicators included loading facilities, social and public facilities, catering facilities, religious facilities, and housekeeping. The chart shown in Figure 20 indicates that a total of $63 \%$ of the pilgrims were not satisfied with the building's religious facilities. A percentage of $40 \%$ of the users' sample indicated their dissatisfaction with housekeeping services and social and public facilities, while $37 \%$ of the users were satisfied with loading services.

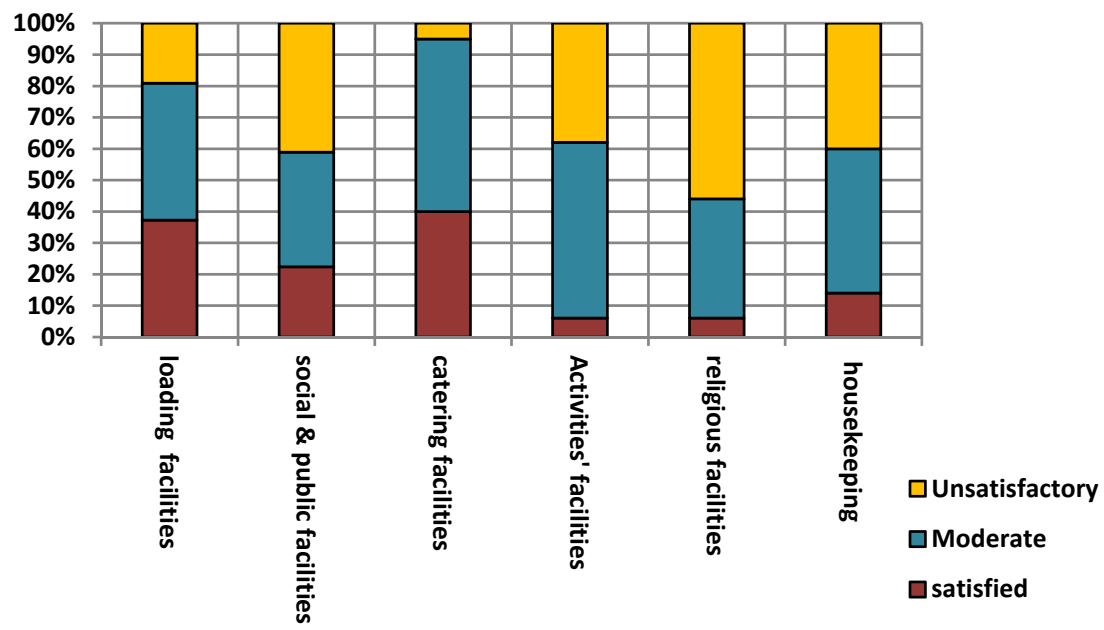

Figure 20: Overall users' satisfaction 


\section{Conclusions}

POE based on users' satisfaction proves to be an effective and appropriate tool in reaching recommendations on Mina's accommodation buildings performance. The most important conclusion emerging from this study is that utilization of the mountainous area will augment Mina's built environment and its accommodative capacity. However, comprehensive interdisciplinary approach entailing multisystem development should be adopted for Mina's built environment. Any future expansion should be independent from the existing services, traffic networks, and utilities within the Mina valley. Accessibility and connectivity for the mountainous area should be maintained, ensuring linkages to target destinations in Mina in the proposed development project. Since the project is being developed in a mountainous area with limited accessibility, all of the required services (e.g., commercial and health services) should be provided onsite as per site planning standards [15].

Within buildings, the study revealed missing functional areas or being inadequate or badly located. Consequently, there is need to enforce all design and operational governing codes, standards, and best practices for buildings of this type and capacity. Stakeholders and end-users should be given opportunities to participate in the decision-making process relating to the development of space as well as the design of different project phases. The analysis of the results has demonstrated the importance of social and spiritual activities for pilgrims. Indoor and outdoor facilities that are adequate in area and in appropriate locations should, therefore, be provided for the performance of nonstandard religious and social functions. Moreover, central facilities should be provided within the site.

Regarding circulation components of the buildings, the study proved that adequate numbers of elevators should be provided of sufficient capacity and in appropriate locations. All of the floors in a building should be accessible by service elevators. Elevator lobbies should be of a suitable area. The main staircases of buildings should connect all floors. Horizontal corridors should be clearly identifiable and connect all building elements.

Based on the fees pilgrims have paid, a net area of $2.75 \mathrm{~m}^{2}$ per pilgrim should be satisfying. Rooms with different occupancy capacities should be provided with maximum number of 12 persons per room.

\section{Acknowledgement}

The researchers acknowledge the Custodian of the Two Holy Mosques Institute for Hajj Research Institute in Makkah for facilitating the permissions to collect the data required of this research.

\section{References}

[1] Koshak Nabil A., Shehata, Ahmed M., Assessing Environmental Hazards in Mina's Built Environment Using 3D GIS, Al-Azhar University Engineering Journal. 2006. 
[2] Ahmed Shehata, Amr M. Z. Al-Zawahiri. Improving Visual Characteristics of Mina's Built Environment. Prot said university engineering journal. 2007.

[3] Nozha, Y. A. Makkah morphology, Study to identify the geographic, economic, and social zones of the Makkah region. M.Sc. thesis, Umm AlQura University. 2004.

[4] Google Earth, "Makkah"2125'20.03”N 3951'08.51”E. Google Earth. 9/20/2015. 1/21/2015.

[5] Ikpo, I. J. Maintainability indices for public building design. Journal of Building Appraisal, 4(4), 321-327. 2009.

[6] Turpin-Brooks, S. and Viccars, G. "The development of robust methods of post-occupancy evaluation”, Facilities, Vol. 24 Nos 5/6, pp. 177-96, 2006.

[7] Koichi Tsujii, Masakazu Takahashi, Yoshikatsu Fujita, and Kazuhiko Tsuda. Extraction of Accommodation Evaluation by Foreign Tourists with Text Mining, International Journal of Trade, Economics and Finance, Vol. 5, No. 2, pp. 131-135, 2014.

[8] Anderzhon, J. W., Fraley, I. \& Green, M. Design for aging post-occupancy evaluations: Lessons learned from senior living environments. AIA's Design for Aging Review, (New York: John Wiley \& Sons), 2007.

[9] Leung, M. Y., Jingyu Yu Chen \& Dongyu Ting Yuan. A case study exploring FM components for elderly in care and attention homes using post occupancy evaluation. Facilities, 32(11/12), 685-708, 2014.

[10] Passini, R., Rainville, C., Marchand, N. \& Joanette, Y. Wayfinding and dementia: some research findings and a new look at design. Journal of Architectural Planning and Research, 15(2), 133-151, 1998.

[11] Barnes, S. The design of caring environments and the quality of life of older people. Aging and Society, 22 (6), 775-789, 2002.

[12] Kane, G., Heaney, G. \& McGreal, S. Resident participation in the evaluation of external accessibility requirements in housing estates. Facilities, 18(1/2), 45-55, 2000.

[13] Low, L. P. L., Lee, D. T. F. \& Chan, A. W. Y. An exploratory study of Chinese older people's perceptions of privacy in residential care homes. Journal of Advanced Nursing, 57(6), 605-613, 2007.

[14] Adetokunbo, O. I. Post-occupancy evaluation and residents' satisfaction with public housing in Lagos, Nigeria. Journal of Building Appraisal, 6(2), 153-169, 2010.

[15] Ahmed Shehata, Tarek Nahass. "Sustainable technologies in supporting pilgrims' movement within Mashaer areas", The 11th International scientific conference, Makkah City K.S.A., 1-3 September. Organization of Islamic capitals and cities, 2013. 